\title{
Left atrial structural and functional remodelling study in type 2 diabetic patients in sub-saharan Africa: role of left atrial strain by $2 \mathrm{D}$ speckle tracking echocardiography.
}

\author{
Alain Patrick Menanga ${ }^{1}$, Chris Nadège Nganou-Gnindjio ${ }^{2}$, André Jules Ahinaga ${ }^{1}$, Guy \\ Sadeu Wafeu ${ }^{1}$, Lade Viche ${ }^{1}$, Daryl Nzokou ${ }^{3}$, Jerome Boombhi ${ }^{4}$, and Samuel Kingue ${ }^{1}$ \\ ${ }^{1}$ Faculty of Medicine and Biomedical Sciences, University of Yaoundé 1 \\ ${ }^{2}$ Faculty of Medicine and Biomedical Sciences, University of Yaoundé 1 \\ ${ }^{3}$ University of Yaounde I Faculty of Medicine and Biomedical Sciences \\ ${ }^{4}$ FMBS University of Yaounde 1
}

June 15, 2020

\begin{abstract}
Objective: To evaluate the role of peak atrial longitudinal strain (PALS) through speckle tracking 2D echocardiography for the assessment of structural and functional left atrial (LA) remodelling in a type 2 diabetes mellitus (T2DM) population. Methodology: We conducted a cross-sectional study during a 9-month period. Were included T2DM adults aged 18 and above. The variables assessed during the study include age and gender of participants, diabetes characteristics, cardiovascular risk factors, clinical anthropometric and haemodynamic parameters, standard echocardiographic parameters, volume-derived LA functions and 2D PALS. Results: We included a total of 102 patients. The mean age was $58 \pm 11.7$ years and the M/F sex ratio was 1:1.5. Coexistent arterial hypertension (HTN) was observed in more than half $(59.8 \%)$ of the population sample. Mean $2 \mathrm{D}$ PALS was $29.2 \pm 8.9 \%$ with $58.8 \%$ (95\% CI:50.0-68.6) of subjects having a reduced LA strain (i.e. $<32 \%$ ). Reservoir and pump functions were the most altered LA volumetric phasic functions. Mean indexed LA maximal volume was $22.2 \pm 6.8 \mathrm{ml} / \mathrm{m}^{2}$. There was a significant association between abnormal PALS and age, Body mass index (BMI), indexed LA volume, E/E' ratio, LA active ejection fraction (pump function) and LA expansion index (reservoir function). Conclusion: LA remodelling is a recurrent condition in adult T2DM Cameroonians. The Reservoir and pump LA functions were the most affected. Assessment of LA global strain allows early detection of LA remodelling with comparison to LA size standard analyses. Age, BMI, indexed LA volume, E/E' ratio, reservoir and pump LA functions were associated to 2D LA global strain impairment.
\end{abstract}

\section{INTRODUCTION}

The left atrium (LA) is not only a simple passive transport chamber but also a dynamic apparatus that plays an important role in cardiac function by adjusting left ventricular filling through its reservoir, conduit, and contractile functions. LA remodelling refers to the spectrum of pathophysiological changes in atrial structure and mechanical function, and within the electric, ionic, and molecular environments of the LA. This remodelling most often occurs in response to stresses imposed by conditions such as hypertension, heart failure, type 2 diabetes mellitus (T2DM), and obesity ${ }^{1}$. Remodelling constitutes the basis of atrial cardiomyopathy. It has been recently defined by an expert consensus as a complex of structural, architectural, contractile or electrophysiological modifications affecting the atria with the potential of inducing significant clinical manifestations ${ }^{2}$. It has also been identified as an independent predictor of adverse cardiovascular event in T2DM, a pathology whose prevalence is constantly increasing in sub-Saharan Africa ${ }^{3,4}$ 
Analysis of LA size through standard echocardiographic methods is commonly used but has proven to be inaccurate in the assessment of LA remodelling ${ }^{5}$. They are subjective, depend on the level of expertise of the operator, lack sensibility in detecting early abnormalities and do not apprehend all the components of myocardial function ${ }^{6}$. Bidimensional speckle tracking echocardiography allow a direct and angle-independent analysis of myocardial deformation, thus giving sensitive and reproductible myocardial dysfunction indices which overcome the limits of Doppler-derived measurements ${ }^{7}$. Evaluation of LA deformation mechanics could help in detecting LA dysfunction earlier than the standard measurement methods ${ }^{8}$.

This study aims to evaluate the role of peak atrial longitudinal strain through speckle tracking 2D echocardiography for the assessment of structural and functional LA remodelling in a T2DM adult population in Cameroon.

\section{METHODS}

\section{Study design and population}

A cross-sectional study was conducted during a 9-month period (from January 2019 to September 2019). Patients were recruited at National Obesity Centre and the Centre for treatment of Diabetes and Hypertension of the Yaoundé Central Hospital. We included in the study, T2DM adults aged 18 and above, no matter the duration of diabetes follow up, with no history of a proven cardiac disease caused by a condition other than hypertension (HTN) or T2DM such as coronary artery disease, significant valvular heart disease, obstructive hypertrophic cardiomyopathy, atrial fibrillation or flutter.

\section{Data collection}

A thorough clinical examination was carried out at inclusion. The variables assessed at this point of the study included, the age and gender of participants, diabetes characteristics, cardiovascular risk factors, clinical, anthropometric and haemodynamic parameters. The clinical examination was followed by a resting electrocardiographic recording.

\section{Echocardiography}

Transthoracic echocardiography was performed in all patients using a machine equipped with a $5 \mathrm{MHz}$ X5-1 probe (Plilips iE33) and the QLAB Ultrasound cardiac analysis software for strain measurement. Standard echocardiographic parameters were obtained, these included LV ejection fraction through Simpson's Biplane method, LV mass index and LV diastolic function through Tissue Doppler imaging derived E and E' peak velocities at the lateral mitral annulus. The biplane Simpson's method was used for calculation of LA volumes. Left atrial volume was planimetered in the four-chamber and two-chamber views by tracing the endocardial border (pulmonary vein confluence and LA appendage were excluded) ${ }^{9}$.

Maximum LA volume (LA max) was obtained at left ventricular (LV) end-systole, from the 2D frame, just before the mitral valve opened. Pre-atrial volume (Vpre-A) was obtained from the diastolic frame, just before the mitral valve reopened as the result of atrial contraction. Left atrial minimum volume (LA min) was assessed at LV end-diastole, from the smallest volume seen after LA contraction.

Left atrial phasic function assessment was done using the following formulas ${ }^{10}$ :

Reservoir function: LA emptying fraction total $=(($ LA $\max -$ LA $\min ) /$ LA max $) \times 100 \%$; expansion index $=((\mathrm{LA} \max -\mathrm{LA} \min ) / \mathrm{LA} \min ) \times 100 \%$

Conduit function: Passive emptying volume $=$ LA max - Vpre-A; passive LA emptying fraction $=(($ LA $\max$ - Vpre-A)/LA max) $\times 100 \%$; 
Contractile function: LA active emptying fraction $=(($ LA pre-A - LA min $) /$ LA pre-A $) \times 100 \%$; LA active emptying volume $=\mathrm{V}$ pre-A - LA min.

The echocardiographic evaluation was concluded by peak atrial longitudinal strain (PALS) measurement by $2 \mathrm{D}$ speckle tracking echocardiography. Apical four- and two-chamber views were obtained using $2 \mathrm{D}$ greyscale echocardiography for speckle-tracking analysis. This was performed during end-expiratory breathhold and stable ECG recording. An adequate greyscale image that allowed separation of myocardial tissue and surrounding structures was obtained. Three consecutive cardiac cycles were recorded and averaged. The QLAB software allowed offline semi-automated analysis of speckle-based strain. The endocardial surface of the LA was traced manually in both four- and two-chamber views by a three-point-and-click approach. The system then automatically generates an epicardial surface tracing (Figure 1). The region of interest was thus created, and this was then manually adjusted as needed to allow for adequate speckle tracking ${ }^{11}$. A PALS value less than $32 \%$ was considered abnormal.

\section{Statistical analysis}

Statistical analysis was performed with SPSS version 25.0 software. Continuous variables were expressed as mean \pm standard deviation (SD), while categorical variables were described with number of subjects (percentages). Means and proportions were respectively compared with the Student t test and Chi square or Fisher exact test. Multivariate linear regression analysis was used to identify possible independent determinants of abnormal PALS. Independent variables with a p-value less than 0.05 on bivariate analysis were included in the multivariate model. A p value $<0.05$ was considered statistically significant.

\section{RESULTS}

\section{Baseline characteristics}

Of the 102 individuals, 61 were female $(59.8 \%)$ with a male to female sex ratio of 1:1.5 and the mean age was $58 \pm 11.7$ years. More than half of the population had hypertension associated to T2DM, precisely $59.8 \%$ of the subjects. The mean duration of diabetes was $7.4 \pm 6.2$ years and 29 patients $(28.4 \%)$ presented micro vascular complications of diabetes. About $\frac{3}{4}$ of the study population $(77.9 \%)$ had a treatment regimen including at least one oral antidiabetic drugs and slightly more than $\frac{1}{4}(28 \%)$ had insulin in their treatment. The study population was globally in overweight with a mean body mass index (BMI) of $28.9 \pm 5.6 \mathrm{~kg} / \mathrm{m}^{2}$ (Table I).

\section{LA volumetric parameters and LA global strain}

The mean maximum indexed LA volume (LAVi) was $22.2 \pm 6.8 \mathrm{ml} / \mathrm{m}^{2}$. The reservoir and contractile LA functions were the most altered with respect to normal population values. The mean peak atrial longitudinal strain at the reservoir phase for the total population was $29.2 \pm 8.9 \%$, with a prevalence of abnormal PALS of $58.8 \%$ ( $95 \%$ CI : $50.0-68.6$ ).

\section{Variation of clinical and echocardiographic parameters with PALS}

Individuals with a reduced PALS were significantly older $(60.4 \pm 11.1$ vs $54.6 \pm 11.9$ years, $\mathrm{p}=0.013)$, had a greater BMI $\left(30.1 \pm 6.0\right.$ vs $\left.27,1 \pm 4.4 \mathrm{~kg} / \mathrm{m}^{2}, \mathrm{p}=0.007\right)$, higher systolic blood pressure $(\mathrm{SBP})(\mathrm{p}=0.034)$ and greater E/E' ratio $(12.1 \pm 4.6$ vs $8.9 \pm 2.3, \mathrm{p}<0.001)$. Furthermore, LAVi $(\mathrm{p}=0.006)$, LA expansion index $(\mathrm{p}<0.001)$, LA global $(\mathrm{p}<0.001)$ and active $(\mathrm{p}=0.002)$ ejection fractions were significantly higher in subjects with abnormal PALS (Table II).

On multivariate analysis, $\mathrm{E} / \mathrm{E}$ ' ratio (adjusted $\mathrm{p}=0.032$ ) and BMI (adjusted $\mathrm{p}=0.022$ ) were independently associated to abnormal PALS after adjustment for all the significant variables. 


\section{DISCUSSION}

We assessed the role of LA global longitudinal strain by evaluating the LA remodeling in a Cameroonian T2DM adults. We included a group of diabetic patients, predominantly females, with more than half of them having coexistent hypertension. Given that global cardiovascular risk is very high in diabetic patients, its reduction constitutes a major treatment objective ${ }^{12}$. Despite the high proportion of hypertensive patients in the population, we found only à third of them with a renin-angiotensin-aldosterone system blocker in their treatment regimen. Thus, reflecting the difficulties in applying ESC/ESH treatment recommendations

13 in Africa, especially in Cameroon, which could be linked to the relative high cost of these medications in our context, making them less available to the majority of hypertensive patients. Mean LVEF was $63.1 \%$, corresponding to the classical presentation of patients with cardiac disease related to diabetes, where diastolic dysfunction is the main abnormality at the early stage ${ }^{14}$.

LA structural remodelling is classically expressed by the measurement of the LAVi by 2D (or 3D) echocardiography ${ }^{1}$. Increased LAVi is a surrogate marker of increased and chronic pressure overload and is a key measurement used in clinical practice to assess diastolic dysfunction of the LV ${ }^{15}$. The mean value of LAVi $\left(22 \pm 6 \mathrm{ml} / \mathrm{m}^{2}\right)$ in the study was within the normal reference range of the American society of Echocardiography ${ }^{16}$. However, we observed greater alterations of the reservoir function (LA global ejection fraction) and the contractile function.

PALS was significantly reduced in the study population compared to a non-diabetic black African population in South Africa $(29.2 \pm 9 \text { vs } 39 \pm 8.3, \mathrm{p}<0,001)^{11}$. Meanwhile this results is similar to those found by Markman and al. in a diabetic population with a mean PALS of $28.5 \pm 11.7 \%^{17}$. Concerning the role of PALS in early detection diastolic and LA dysfunction, it is important to highlight that LA strain was markedly reduced in many patients with normal LAVi. In 2016, Bassam and al, had similar results in a group of hypertensive subjects in whom LA strain measured by speckle tracking echocardiography allowed early detection of LA dysfunction even before LA dilatation ${ }^{7}$.

Finally, univariate linear regression allowed to highlight a significative negative association of PALS with age, BMI, SBP, E/E' ratio and LAVi. The reservoir (LA expansion index and LA global ejection fraction) and the contractile functions were positively correlated to PALS. Cardiac disease during diabetes leads to atrial fibrosis with consequent reduced atrial compliance ${ }^{18}$. Muranaka and al, also suggested that LA fibrotic modifications during T2DM are responsible for reduced phasic functions determined by LA strain ${ }^{19}$.

This study had several limitations: (i) LA strain measurement lacks a criterion standard - strain values vary with different software packages; (ii) the quantitative values defined for LA strain are vendor-specific; (iii) the software used for assessing strain does not have a specific mode for LA strain study; and (iv) coronarography which is the gold standard to exclude coronary artery disease could not be performed.

\section{CONCLUSION}

LA remodeling is a recurrent condition in the adult T2DM population. The reservoir and pump LA functions were the most affected. Assessment of LA global strain allows early detection of LA remodeling and dysfunction with comparison to LA size standard analyses and LV filling pressures determined by E/E' ratio respectively. Age, BMI, indexed LA volume, E/E' ratio, reservoir and pump LA functions were associated to 2D LA global strain impairment.

\section{ACKNOWLEDGEMENTS}

The authors gratefully acknowledge all the volunteers who accepted to participate to this study, the National centre for Obesity and The Centre for treatment of Diabetes and Hypertension of the Yaounde Central 
Hospital.

\section{CONFLICT OF INTEREST}

None declared.

\section{AUTHOR CONTRIBUTIONS}

APM: Concept/design, Data analysis/interpretation, Critical revision of article, Approval of article;

CNNG: Concept/design, Data collection, Data analysis/interpretation, Drafting article, Critical revision of article, Approval of article;

AJA: Data collection, data analysis/interpretation, critical revision of article, approval of article;

GSW: Statistics, drafting article, critical revision of article, Approval of article;

LV: Data collection, data analysis/interpretation, critical revision of article, Approval of article,

DNT: Statistics, drafting article, critical revision of article, Approval of article;

JB: Critical revision of article, Approval of article,

SK: Concept/design, Critical revision of article, Approval of article.

\section{REFERENCES}

1. Hoit BD, Wright FL. Left Atrial Remodeling. 2017;10-2.

2. A G. EHRA/HRS/APHRS/SOLEAECE expert consensus on atrial cardiomyopathies: definition, characterization, and clinical implication. Heart Rhythm. 2017;14:e3-40.

3. Zoppini G, Bonapace S, Bergamini C, et al. Evidence of left atrial remodeling and left ventricular diastolic dysfunction in type 2 diabetes mellitus with preserved systolic function. Nutr Metab Cardiovasc Dis. 2016;26(11):1026-32.

3. Ning SBG, Hiam MT, All FF, et al. Revue générale Le diabète sucré en Afrique subsaharienne: aspects épidémiologiques, difficultés de prise en charge. 2007;607-11.

5. Douglas PS. The left atrium. J Am Coll Cardiol. 2003;42(7):1206-7.

6. Réant P. Analyse échocardiographique des déformations myocardiques en speckle tracking. Bordx Univ Bordx. 2009;220.

7. Mohamed G, Mamdouh AM. Early Detection of Left Atrial Dysfunction by Speckle Tracking Echocardiography in Hypertensive Patients with Normal Left Atrial Size. Egypt J Hosp Med. 2016;63:143-56.

8. Georgievska-Ismail L, Zafirovska P, Hristovski Z. Evaluation of the role of left atrial strain using twodimensional speckle tracking echocardiography in patients with diabetes mellitus and heart failure with preserved left ventricular ejection fraction. Diab Vasc Dis Res. 2016;13(6):384-94.

9. Lang RM, Bierig M, Devereux RB, et al. Recommendations for chamber quantification: A report from the American Society of Echocardiography's guidelines and standards committee and the Chamber Quantification Writing Group, developed in conjunction with the European Association of Echocardiograph. J Am Soc Echocardiogr. 2005;18(12):1440-63. 
10. Gulmez O, Parıldar H, Cigerli O, et al. General Medicine : Open Access Assessment of Left Atrial Functions in Patients with Prediabetes. 2017;5(5).

11. Meel R, Khandheria BK, Peters F, et al. Left atrial volume and strain parameters using echocardiography in a black population. 2016;1:1-6.

12. Wentworth D, Stamler J, The FOR, et al. age-groups (1-6). Generally, CVD ac-. 1993;16(2):434-44.

13. Esh H, Agabiti E, France MA, et al. 2018 ESC / ESH Guidelines for the management of arterial hypertension The Task Force for the management of arterial hypertension of the European Society of Cardiology ( ESC ) and the European Society of. 2018. 1-98 p.

14. Bounhoure J, Komajda M. Cardiomyopathie Diabétique : une entite specifique ? 2017;325-37.

15. Nagueh SF, Appleton CP, Gillebert TC, et al. Recommendations for the evaluation of left ventricular diastolic function by echocardiography. Eur J Echocardiogr. 2009;10(2):165-93.

16. Meuleman C, Dufaitre G, Haddour N, et al. Mesure echographique de l' oreillette gauche : diametre, surface ou volume? d:3-5.

17. Markman TM, Habibi M, Ambale-Venkatesh B, et al. Left atrial structure and function and cardiovascular events in patients with diabetes mellitus: Results from multi-ethnic study of atherosclerosis (MESA). Vol. 130, Circulation. 2014. p. 1-7.

18. Asbun J, Villarreal FJ. The Pathogenesis of Myocardial Fibrosis in the Setting of Diabetic Cardiomyopathy. J Am Coll Cardiol. 2006;47(4):693-700.

19. Muranaka A, Yuda S, Tsuchihashi K, et al. Quantitative assessment of left ventricular and left atrial functions by strain rate imaging in diabetic patients with and without hypertension. Echocardiography. 2009;26(3):262-71.

Table I: Baseline characteristics, diabetes and cardiovascular risk factors' characteristics

\begin{tabular}{|c|c|c|c|c|c|}
\hline Variables & $\begin{array}{l}\text { Abnormal PALS } \\
(\mathrm{n}=60)\end{array}$ & $\begin{array}{l}\text { Normal PALS (n } \\
=42)\end{array}$ & Total $(\mathrm{n}=102)$ & Crude $\mathrm{p}$ value & $\begin{array}{l}\text { Adjusted } \mathrm{p} \\
\text { value }^{£}\end{array}$ \\
\hline Age (years) & $60.4 \pm 11.05$ & $54.6 \pm 11.9$ & $58 \pm 11.7$ & 0.013 & 0.533 \\
\hline Male, n (\%) & $20(33.3)$ & $21(50)$ & $41(40.2)$ & 0.091 & \\
\hline $\begin{array}{l}\text { Duration of } \\
\text { diabetes } \\
\text { (years) }\end{array}$ & $8.1 \pm 6.9$ & $6.5 \pm 4.8$ & $7.4 \pm 6.2$ & 0.175 & \\
\hline $\begin{array}{l}\text { Glycated } \\
\text { haemoglobin } \\
(\%)\end{array}$ & $7.8 \pm 2.6$ & $6.6 \pm 2.2$ & $7.3 \pm 2.5$ & 0.063 & \\
\hline $\begin{array}{l}\text { Microvascular } \\
\text { complications, } \\
\mathrm{n}(\%)\end{array}$ & $18(30)$ & $11(26.2)$ & $29(28.4)$ & 0.824 & \\
\hline $\begin{array}{l}\text { Macrovascular } \\
\text { complications } \mathrm{n} \\
(\%)\end{array}$ & $3(5)$ & $2(4.8)$ & $5(4.9)$ & 0.956 & \\
\hline $\begin{array}{l}\text { Hypertension, } \\
\mathrm{n}(\%)\end{array}$ & $40(66.7)$ & $21(50)$ & $61(59.8)$ & 0.091 & \\
\hline $\begin{array}{l}\text { Chronic kidney } \\
\text { disease, n (\%) }\end{array}$ & $3(5)$ & $0(0)$ & $3(2.9)$ & 0.266 & \\
\hline $\begin{array}{l}\text { Dyslipidemia, } \\
\mathrm{n}(\%)\end{array}$ & $13(21.7)$ & $4(9.5)$ & $17(16.7)$ & 0.105 & \\
\hline
\end{tabular}




\begin{tabular}{|c|c|c|c|c|c|}
\hline Variables & $\begin{array}{l}\text { Abnormal PALS } \\
(\mathrm{n}=60)\end{array}$ & $\begin{array}{l}\text { Normal PALS (n } \\
=42)\end{array}$ & Total $(\mathrm{n}=102)$ & Crude $\mathrm{p}$ value & $\begin{array}{l}\text { Adjusted p } \\
\text { value }^{£}\end{array}$ \\
\hline $\begin{array}{l}\text { Total } \\
\text { cholesterol } \\
\text { level }(\mathrm{g} / \mathrm{l})\end{array}$ & $1.8 \pm 0.5$ & $1.6 \pm 0.3$ & $1.7 \pm 0.5$ & 0.208 & \\
\hline $\begin{array}{l}\text { Duration of } \\
\text { HTN, (years) }\end{array}$ & $7.4 \pm 5.7$ & $8.6 \pm 6.4$ & $7.8 \pm 5.9$ & 0.430 & \\
\hline $\begin{array}{l}\text { Oral } \\
\text { antidiabetics, } \\
\mathrm{n}(\%)\end{array}$ & $47(78.3)$ & $32(76.2)$ & $79(77.5)$ & 0.799 & \\
\hline Insulin, n (\%) & $17(28.3)$ & $12(28.6)$ & $29(28.4)$ & 0.979 & \\
\hline $\begin{array}{l}\text { ACEi/ARA, n } \\
(\%)\end{array}$ & $24(40)$ & $11(26.2)$ & $35(34.3)$ & 0.148 & \\
\hline Statin, n (\%) & $11(18.3)$ & $5(11.9)$ & $16(15.7)$ & 0.380 & \\
\hline $\mathrm{SBP}(\mathrm{mmHg})$ & $144.5 \pm 21.8$ & $135.2 \pm 21.1$ & $140.6 \pm 21.9$ & 0.034 & 0.937 \\
\hline $\mathrm{DBP}(\mathrm{mmHg})$ & $88.3 \pm 12.2$ & $85.2 \pm 11.5$ & $87 \pm 11.9$ & 0.211 & \\
\hline $\begin{array}{l}\text { Heart rate } \\
(\mathrm{bpm})\end{array}$ & $75.2 \pm 12.5$ & $79.2 \pm 12.4$ & $76.9 \pm 12.6$ & 0.111 & \\
\hline $\mathrm{BMI}\left(\mathrm{Kg} / \mathrm{m}^{2}\right)$ & $30.1 \pm 6.04$ & $27.1 \pm 4.4$ & $28.9 \pm 5.6$ & 0.007 & 0.022 \\
\hline
\end{tabular}

Values are mean \pm standard deviation, number of subjects $(\%)$; HTN $=$ Hypertension; ACEi angiotensinconverting enzyme inhibitors; $\mathrm{ARA}=$ angiotensin receptors antagonists; $\mathrm{SBP}=$ systolic blood pressure; $\mathrm{DBP}=$ diastolic blood pressure; BMI = body mass index ${ }^{£}$ : Adjusted for all significant variables on bivariate analysis $(\mathrm{p}<0.05)$.

Table II:Echocardiographic parameters, LA phasic volumetric functions and peak atrial longitudinal strain.

\begin{tabular}{|c|c|c|c|c|c|}
\hline Variables & $\begin{array}{l}\text { Abnormal PALS } \\
(\mathrm{n}=60)\end{array}$ & $\begin{array}{l}\text { Normal PALS }(\mathrm{n} \\
=42)\end{array}$ & Total $(\mathrm{n}=102)$ & Crude $\mathrm{p}$ value & $\begin{array}{l}\text { Adjusted p } \\
\text { value }^{£}\end{array}$ \\
\hline $\begin{array}{l}\text { LVEF - } \\
\text { Biplane (\%) }\end{array}$ & $62.7 \pm 7.1$ & $63.6 \pm 6.2$ & $63.1 \pm 6.7$ & 0.482 & \\
\hline $\begin{array}{l}\text { LV mass index } \\
\left(\mathrm{g} / \mathrm{m}^{2}\right)\end{array}$ & $78.9 \pm 20.8$ & $74.2 \pm 22.4$ & $77 \pm 21.5$ & 0.282 & \\
\hline $\mathrm{E} / \mathrm{A}$ ratio & $0.8 \pm 0.3$ & $0.8 \pm 0.3$ & $0.8 \pm 0.3$ & 0.546 & \\
\hline E/E' ratio & $12.1 \pm 4.6$ & $8.9 \pm 2.3$ & $10.8 \pm 4.1$ & $<0.001$ & 0.032 \\
\hline $\mathrm{LAVi}\left(\mathrm{ml} / \mathrm{m}^{2}\right)$ & $23.7 \pm 7.1$ & $19.9 \pm 5.7$ & $22.2 \pm 6.8$ & 0.006 & 0.419 \\
\hline $\begin{array}{l}\text { LA total } \\
\text { éjection } \\
\text { volume }(\mathrm{ml})\end{array}$ & $24.4 \pm 7.7$ & $23.5 \pm 9.4$ & $24.1 \pm 8.4$ & 0.584 & \\
\hline $\begin{array}{l}\text { LA passive } \\
\text { éjection } \\
\text { volume }(\mathrm{ml})\end{array}$ & $12.6 \pm 7.1$ & $12.4 \pm 7.1$ & $12.6 \pm 7$ & 0.893 & \\
\hline $\begin{array}{l}\text { LA global } \\
\text { éjection } \\
\text { fraction }\end{array}$ & $55.4 \pm 12.5$ & $65.0 \pm 10.3$ & $59.4 \pm 12.6$ & $<0.001$ & 0.511 \\
\hline $\begin{array}{l}\text { LA expansion } \\
\text { index }(\%)\end{array}$ & $149.2 \pm 74.3$ & $210.4 \pm 93.01$ & $174.4 \pm 87.5$ & $<0.001$ & 0.879 \\
\hline $\begin{array}{l}\text { LA active } \\
\text { éjection } \\
\text { volume (ml) }\end{array}$ & $12.53 \pm 5.4$ & $12.07 \pm 5.4$ & $12.3 \pm 5.4$ & 0.674 & \\
\hline
\end{tabular}




\begin{tabular}{llllll}
\hline Variables & $\begin{array}{l}\text { Abnormal PALS } \\
(\mathrm{n}=60)\end{array}$ & $\begin{array}{l}\text { Normal PALS }(\mathrm{n} \\
=42)\end{array}$ & Total $(\mathrm{n}=102)$ & Crude $\mathrm{p}$ value $^{\text {Adjusted } \mathrm{p}}$ & $\begin{array}{l}\text { Adulue } \\
\text { valu }^{£}\end{array}$ \\
\hline $\begin{array}{l}\text { LA active } \\
\begin{array}{l}\text { éjection } \\
\text { fraction }\end{array}\end{array}$ & $40.6 \pm 14.5$ & $49.3 \pm 10.8$ & $44.2 \pm 13.7$ & 0.002 & 0.069 \\
\hline
\end{tabular}

Values are mean \pm standard deviation; $\mathrm{LVEF}=$ left ventricular ejection fraction; $\mathrm{LV}=$ left ventricular; $\mathrm{E}$ = early diastolic velocity of mitral flow; $\mathrm{A}=$ atrial velocity of mitral flow; $\mathrm{E}^{\prime}=$ early diastolic velocity of mitral annulus; $\mathrm{LAVi}=$ left atrial volume index; $\mathrm{LA}=$ left atrial $;{ }^{£}$ : Adjusted for all significant variables on bivariate analysis $(\mathrm{p}<0.05)$.

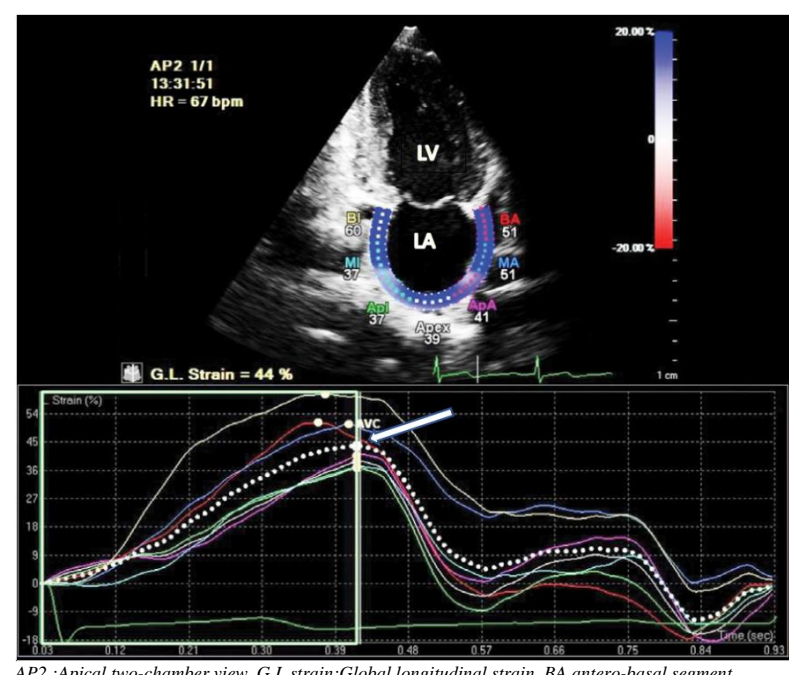

AP2 :Apical two-chamber view, G.L.strain:Global longitudinal strain, BA antero-basal segment, AM:Antero-medial segment, ApA:Antero-apical segment, BI:Infero-basal segment, MI:infero-medial segment, ApI:Infero-apical, HR:Heart rate, LA:Left atrium, LV:Left ventricle.

Figure 1: Two-chamber view depicting peak systolic strain in the reservoir phase. Six segmental longitudinal strain curves are visible, and the dashed curve represents the average value of strain. The peak systolic left atrial strain is indicated by the white arrow. $\mathrm{Y}$-axis represents the strain value in \%, $\mathrm{X}$-axis the duration of a cardiac cycle from $\mathrm{R}$ to $\mathrm{R}$ ECG in seconds. At the top, we have the corresponding M-mode display. 